\title{
Studi Analisis Pengaruh Harmonisa Terhadap Rugi-Rugi Daya Pada Penyulang Menjangan
}

\author{
${ }^{1}$ I D. G. Wisnu Agung Bayuna, ${ }^{2}$ I W. Sukerayasa, W. G. Ariastina
}

\begin{abstract}
The content of harmonics on the electrical system if it exceeds the allowed limit will cause some problems, one of them is causing losses in power distribution networks. To determine the effect of harmonics on power losses in the feeder Menjangan, research conducted by the method of measuring the harmonics of each distribution substation in Menjangan feeders with the help of the software for the next simulation. From the results of the identification of patterns and spectrum curves wave harmonic content of the transformer feeder Menjangan, identical with the commercial load as the load of household and electrical appliances are generally supplied from single-phase Switch Mode Power Supplies. From the measurement of harmonics, the highest content contained in distribution substation at the base are GR088 and GR079. The result of the calculation of the difference between the power loss in the condition without the content of harmonics and power loss in situations where the content of harmonics is $1.7991 \mathrm{~kW}$.
\end{abstract}

Intisari-Kandungan harmonisa pada sistem kelistrikan jika melebihi batas yang diizinkan akan menyebabkan beberapa masalah, salah satunya menimbulkan rugi-rugi jaringan distribusi tenaga listrik. Untuk mengetahui pengaruh harmonisa terhadap rugi-rugi daya di Penyulang Menjangan, dilakukan penelitian dengan metode pengukuran harmonisa pada masingmasing gardu distribusi di Penyulang Menjangan dengan bantuan perangkat lunak untuk selanjutnya dilakukan simulasi. Dari hasil identifikasi pola kurva gelombang dan spectrum kandungan harmonisa pada transformator di Penyulang Menjangan, identik dengan beban komersial seperti beban rumah tangga serta peralatan elektronik yang umumnya disuplai dari single-phase Switch Mode Power Supplies. Dari hasil pengukuran harmonisa, kandungan tertinggi terdapat pada gardu distribusi di bagian pangkal yaitu GR088 dan GR079. Hasil perhitungan selisih antara rugi-rugi daya pada kondisi tanpa kandungan harmonisa dan rugi-rugi daya pada kondisi dengan kandungan hamonisa adalah $1,7991 \mathrm{~kW}$.

Kata Kunci- Kondisi tanpa Harmonisa, Kondisi dengan Harmonisa, Rugi Daya, Penyulang Menjangan.

\section{PENDAHULUAN}

Penyaluran daya listrik di kawasan Gilimanuk dan sebagian Singaraja disupply oleh Penyulang Menjangan yang bersumber dari Trafo-2 10 MVA Gardu Induk

${ }^{1}$ Jurusan Teknik Elektro, Fakultas Teknik Universitas Udayana, Kampus Bukit Jimbaran, Bali, 80361 INDONESIA (e-mail: dewagedewisnu@gmail.com)

${ }^{2}$ Jurusan Teknik Elektro dan Komputer Fakultas Teknik Universitas Udayana, Jln. Jalan Kampus Bukit Jimbaran 80361 INDONESIA (telp: 0361-703320; fax: 0361-4321; e-mail: sukerayasa@unud.ac.id,w.ariastina@unud..ac.id)
Gilimanuk. Penyulang ini berbentuk konfigurasi jaringan distribusi $20 \mathrm{kV}$ tipe Radial dengan 69 buah Transformator distribusi.Pada saat ini kondisi Penyulang Menjangan memiliki drop tegangan rata-rata yang cukup tinggi yaitu sebesar 10,22\% [1]. Pengukuran awal di tiga gardu pada Penyulang Menjangan menunjukkan bahwa harmonisa arus untuk gardu pangkal (GR 088) $=22,2 \%$ [1], gardu tengah $(\mathrm{GR}$ $058)=5 \%$ [1], dan gardu ujung $($ GR 016) $=9,7 \%$ [1]. Dari hasil pengukuran awal di tiga gardu tersebut diperoleh hasil harmonisa yang cukup tinggi sebesar 22,2\% yang letaknya pada gardu pangkal (GR 088) [1].

Pada penelitian sebelumnya oleh [2] telah mengulas tentang pengaruh distorsi harmonisa pada beban terhadap rugi-rugi transformator yang juga berdampak terhadap unjuk kerja transformator. Penelitian tersebut menganalisis harmonisa dan rugi-rugi daya transformator pada sistem tegangan tinggi 150/20 kV dari berbagai lokasi di gardu induk PT. PLN (Persero) Region Jakarta dan Banten.

Berdasarkan pemaparan permasalahan tersebut, maka dalam penelitian ini menganalisis mengenai pengaruh harmonisa terhadap rugi-rugi daya di sisi tegangan menengah yaitu Penyulang Menjangan. Dengan menggunakan bantuan perangkat lunak untuk simulasi harmonic analysis, selanjutnya hasil analisis yang didapat akan dilakukan perhitungan rugi-rugi daya. Dengan demikian dapat diketahui perbandingan rugi - rugi daya pada saluran saat kondisi tanpa kandungan harmonisa dan saat kondisi dengan kandungan harmonisa pada Penyulang Menjangan.

\section{HARMONISA PADA SISTEM TENAGA LISTRIK}

Harmonik mengacu pada [3], didefenisikan sebagai tegangan ataupun arus sinusoidal yang mempunyai kelipatan frekuensi sistem pasokan tenaga listriknya sebagaimana yang dirancang untuk dioperasikan $(50 \mathrm{~Hz}$ ataupun $60 \mathrm{~Hz})$. Kemudian menurut [4], mendefenisikan harmonik sebagai tegangan ataupun arus sinusoida yang mempunyai kelipatan bulat dari frekuensi dimana sistem tenaga listrik pasokannya dirancang untuk dioperasikan (atau disebut juga dengan terminology : frekuensi fundamental).

Cacat gelombang yang disebabkan oleh interaksi antara bentuk gelombang sinusoidal sistem dengan komponen gelombang lain dikenal dengan harmonisa. THD didefinisikan sebagai persentase total komponen harmonisa terhadap komponen fundamentalnya. [5]

Harmonisa disebabkan oleh adanya beban nonlinear yang digunakan dalam sistem tenaga listrik. Peralatan seperti converter, penyearah, adjustable speed drive untuk mengendalikan motor-motor industri, thyristor controlled reactor, serta berbagai peralatan yang didasarkan pada proses pensaklaran dapat menimbulkan terjadinya harmonisa. Sedangkan untuk beban, yang dapat menimbulkan harmonisa 
antara lain electric arc furnace, induction furnace, serta mesin las, dimana beban tersebut berubah-ubah dari waktu ke waktu dengan cepat secara nonlinier. [6]

\section{A. Sumber Harmonisa}

Sumber-sumber harmonisa dibagi berdasarkan sumber harmonik dari beban komersial dan sumber harmonik dari beban industri sebagai berikut [7] :

- Sumber harmonik dari beban komersial dan fasilitas komersial seperti beban rumah tangga, kantor yang kompleks, pusat perbelanjaan, rumah sakit, dan akses data intern didominasi oleh lampu flourecent dengan ballast elektronik, Pengatur kecepatan (adjustable-speed driver) digunakan pada pemanasan (heating), Ventilasi (Ventilation), dan pendingin ruangan (AC), dan peralatan elektronik sensitive lainnya pada umumnya disuplai dari single-phase switchmode power supplies (SMPS).

Wave Form

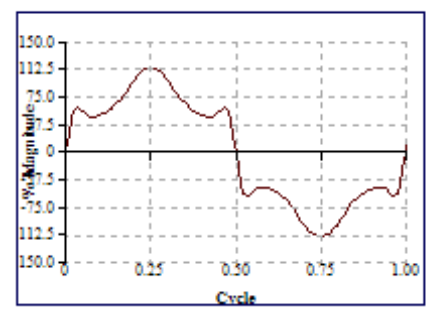

Gambar 1: Gelombang Arus dan Spektrum Harmonik pada SMPS

- Sumber harmonisa dari kelompok beban industri ini merupakan sumber harmonisa yang sangat penting, karena beban industri pada umunnya menghasilkan harmonisa yang cukup besar dibandingkan dengan beban komersial. Industri sering memanfaatkan fasilitas kapasitor bank untuk memperbaiki faktor daya untuk menghindari biaya penalti. Aplikasi kapasitor untuk perbaikan faktor daya memperbesar harmonik arus dari beban nonlinier, sehingga menimbulkan resonansi.
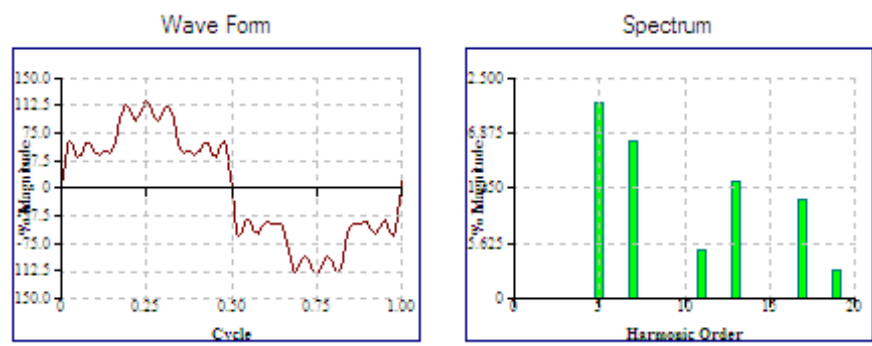

Gambar 2:Gelombang Arus dan Spectrum Harmonik pada konveterter 3 phasa PWM-type ASD

\section{B. Pengaruh Harmonik pada Komponen Sistem Distribusi}

Frekuensi harmonik yang lebih tinggi dari frekuensi kerjanya akan mengakibatkan penurunan efisiensi atau terjadi kerugian daya. Secara khusus, efek atau dampak jangka panjang yang ditimbulkan oleh harmonik pada sistem tenaga listrik sebagai berikut [6] :

- Pemanasan kapasitor
- Tegangan non-sinusoidal yang diterapkan pada mesin listrik dapat meningkatkan rugi inti dan rugi belitan, serta pemanasan lebih.

- Frekuensi harmonik yang lebih tinggi dari frekuensi kerjanya akan mengakibatkan penurunan efisiensi dan pada akhirnya mengakibatkan kerugian daya pada transformator.

- Pemanasan pada kabel dan peralatan lainnya, rugi-rugi kabel yang dilewati oleh arus harmonik akan semakin besar.

\section{Rugi-Rugi pada Penghantar}

Rugi-rugi yang terjadi pada penghantar bergantung terhadap besar arus yang mengalir padanya dan besar tahanan yang dimiliki penghantar tersebut. Dengan mengalirnya arus harmonisa $\left(I_{r m s}\right)$ pada penghantar, maka akan menyebabkan terjadinya penambahan panas sehingga terjadi peningkatan rugi-rugi $I^{2} R$ pada penghantar tersebut. Dengan demikian besarnya rugi-rugi penghantar $\left(P_{\text {Loss }}\right)$ akibat terdapatnya komponen harmonisa di dalam arus beban dapat dihitung [8] :

$\mathbf{P}_{\text {lass }}=\sum_{n=1}^{m} \mathrm{I}_{\mathrm{n}}^{2} \cdot \mathbf{R}_{\mathrm{n}}$

dengan:

$\mathrm{P}_{\text {Loss }}=$ rugi-rugi penghantar (watt)

$\mathrm{I}_{\mathrm{n}} \quad=$ arus komponen harmonisa (ampere)

$\mathrm{R}_{\mathrm{n}} \quad=$ tahanan untuk frekuensi harmonik (ohm)

\section{Rugi-Rugi pada Transformator}

Rugi-rugi transformator dikelompokkan menjadi rugi tanpa beban dan rugi berbeban (load losses). Rugi-rugi transformator keseluruhan sebagai berikut [2] :

$\mathrm{P}_{\mathrm{TL}}=\mathrm{P}_{\mathrm{NL}}+\mathrm{P}_{\mathrm{LL}}$

dengan:

$\mathrm{P}_{\mathrm{TL}}=$ rugi total transformator

$\mathrm{P}_{\mathrm{NL}}=$ rugi tanpa beban

$\mathrm{P}_{\mathrm{LL}}=$ rugi berbeban

1) Rugi Transformator Tanpa Beban : Susut trafo tanpa beban (beban nol) terdiri dari susut eddycurrent $\left(\mathrm{P}_{\mathrm{EC}}\right)$ dan susut hysterisis. Susut eddy current adalah besaran dari eddy current yang dihasilkan oleh tegangan induksi pada laminasi sebagai respon terhadap alternating flux yang merupakan proporsional dari kuadrat ketebalan laminasi, kuadrat dari frekuensi dan kuadrat dari nilai efektif (rms) kerapatan flux. Menurut [9], susut tanpa beban tidak berpengaruh terhadap arus harmonisa.

2) Rugi Transformator Berbeban : Perhitungan yang digunankan untuk rugi-rugi transformator pada ratingnya dalam per-unit (pu). [2]

$\mathrm{P}_{\mathrm{LL}-\mathrm{R}}(\mathrm{pu})=1+\mathrm{P}_{\mathrm{EC}-\mathrm{R}}(\mathrm{pu})+\mathrm{P}_{\mathrm{OSL}-\mathrm{R}}(\mathrm{pu})$ [2] dengan:

$\mathrm{P}_{\mathrm{LL}-\mathrm{R}} \quad=$ rugi berbeban pada rating transformator.

$\mathrm{P}_{\mathrm{EC}-\mathrm{R}} \quad=$ rugi arus eddy pada belitan pada rating trafo

$\mathrm{P}_{\mathrm{OSL}-\mathrm{R}}=$ rugi sasar lain pada rating transformator

Untuk menghitung kemampuan transformator menggunakan data desain, mengacu kepada [10] dan [11], maka rugi transformator karena mengalirnya arus beban melalui belitan transformator. 
Rugi Ohmik ( $\left.\mathrm{I}^{2} \mathrm{R}\right)$, akibat arus beban mengalir pada konduktor atau belitan dan ini disebut "Rugi $d c$ ".

$\mathrm{P}_{\mathrm{IR}-\mathrm{R}}^{2}=\mathrm{K} \cdot\left[\left(\mathrm{I}_{1-\mathrm{R}}\right)^{2} \cdot \mathrm{R}_{1}\right]+\left[\left(\mathrm{I}_{2-\mathrm{R}}\right)^{2} \cdot \mathrm{R}_{2}\right]$ watt $[10]$

dengan:

$\mathrm{P}_{\mathrm{IR}-\mathrm{R}}^{2}=$ rugi Ohmik pada rating transformator.

$\mathrm{K}=1.5$ untuk transformator tiga phasa.

$\mathrm{I}_{1-\mathrm{R}} \quad=$ rating arus pada sisi tegangan tinggi primer.

$\mathrm{I}_{2-\mathrm{R}} \quad$ = rating arus pada sisi tegangan rendah sekunder.

$\mathrm{R}_{1} \quad=$ nilai resistansi ( 3 phasa) pada sisi tegangan tinggi.

$\mathrm{R}_{2} \quad$ = nilai resistansi (3 phasa) pada sisi tegangan rendah.

Rugi Sasar/Stray Losses $\left(P_{T S L-R}\right)$ merupakan rugi-rugi transformator berbeban $\left(P_{L L-R}\right)$ dikurangi Rugi Ohmik atau Rugi dc $\left(P_{I R-R}^{2}\right)$.

$\mathrm{P}_{\mathrm{TSL}-\mathrm{R}}=\mathrm{P}_{\mathrm{LL}-\mathrm{R}}-\left\{\mathrm{K} \cdot\left[\left(\mathrm{I}_{1-\mathrm{R}}\right)^{2} \cdot \mathrm{R}_{1}\right]+\left[\left(\mathrm{I}_{2-\mathrm{R}}\right)^{2} \cdot \mathrm{R}_{2}\right]\right\}$ watt $[11]$

dengan :

$\mathrm{K}=1.5$ untuk transformator tiga phasa

$\mathrm{P}_{\mathrm{TSL}-\mathrm{R}}=$ rugi sasar total sesuai rating

$\mathrm{P}_{\mathrm{LL}-\mathrm{R}}=$ rugi berbeban sesuai rating

$\mathrm{R}_{1} \quad$ = nilai resistansi (3phasa pada sisi tegangan tinggi

$\mathrm{R}_{2} \quad=$ nilai resistansi (3phasa) pada sisi tegangan rendah

$\mathrm{I}_{1-\mathrm{R}} \quad=$ rating arus pada sisi tegangan tinggi primer

$\mathrm{I}_{2-\mathrm{R}} \quad=$ rating arus pada sisi tegangan rendah sekunder

Asusmsi yang digunakan mengacu pada [12] untuk type transformator dengan pendingin minyak, untuk mendapatkan rugi arus eddy $\left(\mathrm{P}_{\mathrm{EC}-\mathrm{R}) \text {. }}\right.$

$\mathrm{P}_{\mathrm{EC}-\mathrm{R}}=\mathrm{P}_{\mathrm{TSL}-\mathrm{R}} \times 0.33$ watt

Rugi sasar lain $\left(\mathrm{P}_{\mathrm{OSL}}\right)$ pada inti dan metal serta dinding transformator akibat terpotongnya fluks sasar.

$\mathrm{P}_{\mathrm{OSL}-\mathrm{R}}=\mathrm{P}_{\mathrm{TSL}-\mathrm{R}}-\mathrm{P}_{\mathrm{EC}-\mathrm{R}}$ watt

dengan :

$\mathrm{P}_{\mathrm{OSL}-\mathrm{R}}=$ rugi sasar lain sesuai ratingnya

$\mathrm{P}_{\mathrm{TSL}-\mathrm{R}}=$ rugi sasar total sesuai ratingnya

$\mathrm{P}_{\mathrm{EC}-\mathrm{R}} \quad=$ rugi arus eddy sesuai ratingnya

Faktor harmonisa arus eddy belitan didapatkan dengan:

$F_{\mathrm{FL}}=\left(\sum_{\mathrm{n}=1}^{\mathrm{mak}}\left(\frac{\mathrm{L}_{\mathrm{n}}}{\mathrm{l}}\right)^{2} \mathrm{n}^{2}\right) /\left(\sum_{\mathrm{n}=1}^{\mathrm{mak}}\left(\frac{\mathrm{m}_{\mathrm{n}}}{\mathrm{l}}\right)^{2}\right)$

dengan :

$\mathrm{F}_{\mathrm{HL}}=$ faktor harmonisa untuk rugi arus eddy belitan.

$\mathrm{n}=$ harmonisa orde ke-n

$\mathrm{I}_{\mathrm{n}} \quad$ = arus dengan komponen harmonisa ke-n

$\mathrm{I}_{1} \quad=$ arus beban fundamental (ampere)

Faktor harmonisa untuk rugi sasar lain diperoleh dengan

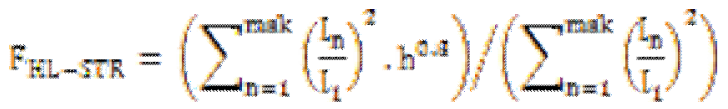

dengan :

$\mathrm{F}_{\mathrm{HL}-\mathrm{STR}}=$ Faktor harmonisa untuk rugi sasar lain.

$\mathrm{n} \quad=$ Harmonisa orde ke-n

$\mathrm{I}_{\mathrm{n}} \quad=$ Arus dengan komponen harmonisa ke-n

$\mathrm{I}_{1} \quad=$ Arus beban fundamental (ampere)
Rugi transformator berbeban dengan adanya harmonisa.

$\mathrm{P}_{\mathrm{LL}}(\mathrm{pu})=\mathrm{P}_{\mathrm{I} \text { R-n }}^{2}+\left[\left(\mathrm{F}_{\mathrm{HL}} \times \mathrm{P}_{\mathrm{EC}}\right)+\left(\mathrm{F}_{\mathrm{HL}-\mathrm{STR}} \times \mathrm{P}_{\mathrm{OSL}}\right)\right][2]$

dengan :

$\mathrm{P}_{\mathrm{LL}}=$ Total Rugi Transformator Berbeban Akibat Harmonisa (watt)

$\mathrm{P}_{\mathrm{I} \text { R-n }}^{2}=$ Rugi dc I'R harmonisa (watt)

$\mathrm{F}_{\mathrm{HL}} \quad=$ faktor harmonisa untuk rugi arus eddy belitan

$\mathrm{P}_{\mathrm{EC}} \quad=$ rugi arus eddy belitan pada transformator berbeban (watt)

$\mathrm{F}_{\mathrm{HL}-\mathrm{STR}}=$ faktor susut akibat arus harmonisa pada other stray loss

$\mathrm{P}_{\mathrm{OSL}} \quad=$ rugi sasar lain pada transformator berbeban (watt)

\section{METODE PENELITIAN}

Dalam penelitian ini dilakukan pengukuran kandungan harmonisa pada masing-masing transformator di Penyulang Menjangan. Dari pengukuran kandungan harmonisa tersebut akan didapatkan hasil pengukuran berupa arus, tegangan, cos $\phi$, harmonisa arus (THDi).

Simulasi harmonic analysis menggunakan bantuan perangkat lunak ETAP PowerStation. Selanjutnya hasil dari eksekusi simulasi harmonic analysis tersebut berupa arus fundamental dan arus r.m.s (arus dengan kandungan harmonisa). Arus fundamental digunakan untuk menghitung rugi-rugi daya penghantar pada kondisi tanpa kandungan harmonisa, sedangkan arus r.m.s akan digunakan untuk perhitungan rugi-rugi daya penghantar dalam kondisi dengan kandungan harmonisa. Selanjutnya berdasarkan data hasil pengukuran harmonisa pada transformator, dilakukan perhitungan rugi-rugi daya pada masing-masing transformator dalam kondisi tanpa kandungan harmonisa dan kondisi dengan kandungan harmonisa.

\section{IV.PEMBAHASAN}

\section{A. Gambaran Umum Penyulang Menjangan}

Salah satu wilayah kerja PT. PLN (Persero) Distribusi Bali Area Bali Utara yang memiliki cakupan yang cukup luas dan panjang yakni berada di daerah Gilimanuk menuju GerokgakSingaraja. Daerah tersebut merupakan salah satu daerah di wilayah bali utara dengan tingkat pertumbuhan penduduk dan perkembangan industri pariwisata yang semakin meningkat, sehingga kebutuhan akan listrik semakin meningkat.

Kebutuhan listrik untuk daerah Gilimanuk dan GerokgakSingaraja tersebut disuplai dari GI Gilimanuk melalui transformator II melalui Penyulang Menjangan dimana dalam keadaan normal Penyulang Menjangan beroperasi secara radial yang terdiri dari 69 transfornator distribusi yang tersebar sepanjang salurannya, serta panjang salurannya mencapai 64,373 km.

\section{B. Hasil Pengukuran THD Penyulang Menjangan}

Data hasil pengukuran THD yang digunakan dalam penelitian ini adalah Total Harmonic Distortion arus (THDi). Dari data hasil pengukuran THDi dapat diketahui bahwa nilai kandungan harmonisa arus tertinggi yang terukur terdapat 
pada Transformator di bagian pangkal Penyulang Menjangan yaitu GR088 dan GR079 yang dapat dilihat pada table I berikut.

TABEL I

DATA HASIL PENGUKURAN THD PENYULANG MENJANGAN

\begin{tabular}{|c|c|c|c|c|c|c|}
\hline \multirow{2}{*}{$\begin{array}{c}\text { Harmonisa } \\
(\%)\end{array}$} & \multicolumn{4}{|c|}{ Uraian Transformator } \\
\cline { 2 - 7 } & \multicolumn{3}{|c|}{$\begin{array}{c}\text { GR088 } \\
\text { (100 kVA) }\end{array}$} & \multicolumn{3}{c|}{$\begin{array}{c}\text { GR079 } \\
(\mathbf{1 6 0 k V A )})\end{array}$} \\
\cline { 2 - 7 } & $\mathbf{R}$ & $\mathbf{S}$ & $\mathbf{T}$ & $\mathbf{R}$ & $\mathbf{S}$ & $\mathbf{T}$ \\
\hline THDi & 27,56 & 24,70 & 23,60 & 21,47 & 22,70 & 31,80 \\
\hline $\mathrm{n}=3$ & 21,9 & 20,4 & 19,5 & 18,3 & 19,4 & 26,2 \\
\hline $\mathrm{n}=5$ & 12,3 & 12,6 & 10,3 & 9,5 & 10,6 & 15,1 \\
\hline $\mathrm{n}=7$ & 8,0 & 7,8 & 7,7 & 5,8 & 6,2 & 11,4 \\
\hline $\mathrm{n}=9$ & 6,9 & 3,6 & 6,0 & 1,3 & 3,9 & 7,9 \\
\hline $\mathrm{n}=11$ & 3,8 & 0,6 & 2,8 & 0,3 & 1,5 & 3,8 \\
\hline $\mathrm{n}=13$ & 0,9 & 1,2 & 0,2 & 0,1 & 0,5 & 0,8 \\
\hline $\mathrm{n}=15$ & 1 & 0,9 & 1,2 & 0,7 & 0,7 & 0,8 \\
\hline $\mathrm{n}=17$ & 0,7 & 0,5 & 0,3 & 0 & 0,3 & 0,3 \\
\hline $\mathrm{n}=19$ & 0,3 & 0,6 & 0,8 & 0,3 & 0,4 & 0,9 \\
\hline
\end{tabular}

C. Analisis Harmonic Load Flow dengan Program ETAP PowerStation

Langkah awal yang dilakukan adalah dengan menggambar secara kesuluruhan diagram segaris Penyulang Menjangan selanjutnya memasukan data - data yang diperlukan yaitu : data beban Jaringan Tegangan Menengah, data hasil pengukuran THDi, data panjang, diameter, impedansi, dan jenis penghantar kemudian dilakukan running harmonic analysis load flow pada ETAP PowerStation yang nantinya menghasilkan nilai arus fundamental dan juga arus r.m.s $\left(I_{r m s}\right)$ saluran. Data hasil eksekusi program ETAP PowerStation didapatkan saluran MVTIC 1 yang memiliki nilai tertinggi yang dapat dilihat pada table II.

TABEL II

DATA HASIL PROGRAM ETAP HARMONIC ANALYSIS

\begin{tabular}{|c|c|c|c|c|c|c|}
\hline \multirow{2}{*}{$\begin{array}{c}\text { Uraian } \\
\text { Saluran }\end{array}$} & \multicolumn{3}{|c|}{$\begin{array}{c}\text { Arus Fundamental } \\
\text { (Ampere) }\end{array}$} & \multicolumn{3}{c|}{$\begin{array}{c}\text { Arus r.m.s } \\
\text { (Ampere) }\end{array}$} \\
\cline { 2 - 7 } & $\mathbf{R}$ & $\mathbf{S}$ & $\mathbf{T}$ & $\mathbf{R}$ & $\mathbf{S}$ & $\mathbf{T}$ \\
\hline $\begin{array}{c}\text { MVTIC } \\
1\end{array}$ & 88,86 & 88,86 & 88,86 & 89,39 & 89,39 & 89,39 \\
\hline
\end{tabular}

D. Perhitungan Rugi-Rugi Penghantar Kondisi Tanpa

Kandungan Harmonisa

Arus fundamental merupakan arus yang mengalir pada penghantar/saluran yang tidak mengandung harmonisa, sehingga arus fundamental yang telah didapatkan dari hasil eksekusi program ETAP Harmonic Analysis akan digunakan dalam menganalisis rugi-rugi penghantar pada kondisi tanpa harmonisa yang mengacu pada (1), dimana In (Arus Harmonisa) diganti dengan menggunakan arus fundamental. Sebagai contoh perhitungan rugi-rugi daya pada penghantar MVTIC 1 sebagai berikut.

Rugi - rugi daya tiga phasa pada saluran MVTIC 1 kondisi tanpa harmonisa :

$\mathrm{I}$ (arus fundamental) $\quad=88,86 \mathrm{~A}$.
$\mathrm{L}$ (panjang penghantar) $=6784 \mathrm{~m}=6,784 \mathrm{~km}$.

$$
\mathrm{R} \text { (Tahanan) } \quad=0,265 \Omega / \mathrm{km} \cdot 6,784 \mathrm{~km}
$$$$
\Delta P=3 \times\left(\sum_{n=1}^{\infty} I_{n}^{2} \cdot R_{n}\right)
$$$$
=1,79776 \Omega
$$

$=3 \times\left(\mathrm{I}_{\text {fundamental }}\right)^{2} \cdot \mathrm{R}$

$=3 \times(88,86)^{2} \times 1,79776$

$=42585,876 \mathrm{Watt}$

$=42,5859 \mathrm{~kW}$

Rugi-rugi daya saluran line/cable MVTIC 1 sebesar $42,5859 \mathrm{~kW}$. Dengan cara perhitungan yang sama seperti di atas, dapat dianalisis rugi-rugi total saluran pada Penyulang Menjangan kondisi tanpa kandungan harmonisa adalah sebesar 199,6573 kW.

\section{E. Perhitungan Rugi-Rugi Transformator Kondisi Tanpa Kandungan Harmonisa}

Dalam perhitungan rugi daya kondisi tanpa harmonisa maka yang digunakan hanya harmonisa arus orde pertama saja (fundamental). Sebagai contoh perhitungan rugi-rugi daya pada Trafo GR88 dengan kapasitas trafo adalah $100 \mathrm{kVA}$ sebagai berikut.

Diketahui data Transformator GR088 sesuai rating adalah sebagai berikut :
Rugi tanpa beban $\left(\mathrm{P}_{\mathrm{NL}}\right)=210$ Watt
Rugi berbeban $\left(\mathrm{P}_{\mathrm{LL}}\right) \quad=1420 \mathrm{Watt}$
Resistan sisi primer $\left(\mathrm{R}_{1}\right)=182 \Omega$
Arus sisi primer $\left(\mathrm{I}_{1}\right) \quad=2.89 \mathrm{Amp}$
Resistan sisi primer $\left(\mathrm{R}_{2}\right)=0.0027 \Omega$
Arus sisi primer $\left(\mathrm{I}_{2}\right) \quad=151.94 \mathrm{Amp}$

Mengacu pada (5) didapatkan total rugi sasar sesuai rating transformator sebagai berikut :

$$
\begin{aligned}
\mathrm{P}_{\mathrm{TSL}-\mathrm{R}} & =\mathrm{P}_{\mathrm{LL}-\mathrm{R}}-\left\{\mathrm{K} \cdot\left[\left(\mathrm{I}_{1-\mathrm{R}}\right)^{2} \cdot \mathrm{R}_{1}\right]+\left[\left(\mathrm{I}_{2-\mathrm{R}}\right)^{2} \cdot \mathrm{R}_{2}\right]\right\} \\
& =1420-\left\{1,5 \times\left[(2,89)^{2} \times 0,182\right]+\left[(151.94)^{2} \times 0,0027\right]\right\} \\
& =1324,222534 \text { Watt } \\
\mathrm{P}_{\mathrm{EC}-\mathrm{R}} & =\mathrm{P}_{\text {TSL-R }} \times 0.33 \\
& =1324,222534 \times 0.33 \\
& =436,993436 \text { Watt } \\
\mathrm{P}_{\text {OSL-R }} & =\mathrm{P}_{\text {TSL-R }}-\mathrm{P}_{\mathrm{EC}-\mathrm{R}} \\
& =1324,222534-436,993436 \\
& =887,2291 \text { Watt } \\
\mathrm{P}_{\mathrm{LL}-\mathrm{R}} & =\mathrm{P}_{\mathrm{I} R-\mathrm{R}}^{2}+\mathrm{P}_{\mathrm{EC}-\mathrm{R}}+\mathrm{P}_{\mathrm{OSL}-\mathrm{R}} \\
1420 & =\mathrm{P}_{\mathrm{I} R-\mathrm{R}}^{2}+436,993436+887,2291 \\
\mathrm{P}_{\mathrm{I} \text { R-R }}^{2} & =95,777 \text { Watt }
\end{aligned}
$$

TABEL III

PERHITUNGAN FAKTOR RUGI HARMONISA TRASFORMATOR GR088 PENYULANG MENJANGAN DALAM $(p u)$ KONDISI TANPA KANDUNGAN HARMONISA

\begin{tabular}{|c|c|c|c|c|c|c|}
\hline $\begin{array}{c}\text { Orde } \\
(\mathbf{n})\end{array}$ & $\left(\mathbf{I n} / \mathbf{I}_{1}\right)$ & $\left(\mathbf{I n} / \mathbf{I}_{1}\right)^{\mathbf{2}}$ & $\left(\mathbf{n}^{2}\right)$ & $\left(\mathbf{I n} / \mathbf{I}_{1}\right)^{{ }^{*} * \mathbf{n}^{2}}$ & $\left(\mathbf{n}^{\mathbf{0 . 8}}\right)$ & $\left(\mathbf{I n} / \mathbf{I}_{1}\right)^{{ }^{*} * \mathbf{n}^{\mathbf{0 . 8}}}$ \\
\hline 1 & 1,000 & 1,000 & 1 & 1,000 & 1,000 & 1,000 \\
\hline & & & & & & \\
\hline TOTAL & & 1,000 & & 1,000 & & 1,000 \\
\hline
\end{tabular}


Dari table III didapatkan :

$$
\begin{aligned}
& F_{\mathrm{FL}}=\left(\sum_{\mathrm{n}=1}^{\mathrm{Eak}}\left(\frac{L_{\mathrm{n}}}{\mathrm{I}}\right)^{2} \mathrm{n}^{2}\right) /\left(\sum_{\mathrm{n}=1}^{\mathrm{mak}}\left(\frac{\mathrm{L}_{\mathrm{n}}}{\mathrm{I}}\right)^{2}\right) \\
& =1,000 / 1,000=1,000 \mathrm{pu}
\end{aligned}
$$

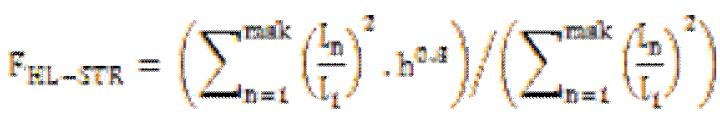

$$
\begin{aligned}
& =1,000 / 1,000=1,000 \mathrm{pu}
\end{aligned}
$$

Untuk transformator yang dibahas dalam penelitian ini adalah transformator yang menggunakan minyak, beban transformator GR88 tercatat 36,67 \% dari kapasitasnya sehingga formula yang digunakan dalam perhitungan untuk menentukan maksimum arus yang dibebankan pada transformator adalah :

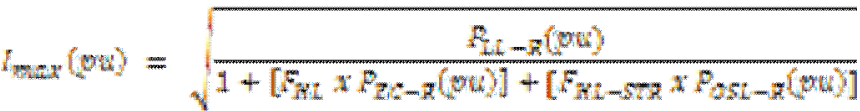

$$
\begin{aligned}
& 0,3667=\frac{\sqrt{P_{L L}}}{\sqrt{1,000}} \\
& (0,3667)^{2} \times(1,000)^{2}=P_{L} \\
& P_{2 L}=0,134469(p u)
\end{aligned}
$$

TABEL IV

HASIL PERHITUNGAN RUGI-RUGI DAYA TRANSFORMATOR GR088 PENYULANG MENJANGAN DALAM KONDISI TANPA KANDUNGAN HARMONISA

\begin{tabular}{|c|c|c|c|c|}
\hline $\begin{array}{c}\text { Type Rugi- } \\
\text { Rgi }\end{array}$ & $\begin{array}{c}\text { Rugi sesuai } \\
\text { Rating } \\
\text { (Watt) }\end{array}$ & $\begin{array}{c}\text { Rugi sesuai } \\
\text { Beban } \\
\text { Trafo } \\
\text { (Watt) }\end{array}$ & $\begin{array}{c}\text { Faktor } \\
\text { Harmonisa } \\
\text { (pu) }\end{array}$ & $\begin{array}{c}\text { Koreksi } \\
\text { Rugi- } \\
\text { Rugi } \\
\text { (Watt) }\end{array}$ \\
\hline $\begin{array}{c}\text { Tidak } \\
\text { berbeban }\end{array}$ & 210 & 210 & & 210 \\
\hline $\begin{array}{c}\text { Rugi } \\
\text { Ohmik } \\
\text { (I' } \mathbf{R})\end{array}$ & 95,777 & 12,879 & & 12,879 \\
\hline $\begin{array}{c}\text { Rugi arus } \\
\text { eddy }\end{array}$ & 436,993436 & 58,762 & 1,000 & 58,762 \\
\hline $\begin{array}{c}\text { Rugi Sasar } \\
\text { Lain }\end{array}$ & 887,2291 & 119,305 & 1,000 & 119,305 \\
\hline Rugi Total & & & & $\mathbf{4 0 0 , 9 4 6}$ \\
\hline
\end{tabular}

Berdasarkan hasil perhitungan pada tabel IV diketahui rugirugi daya total transformator GR088 Penyulang Menjangan sesuai beban transformator dalam kondisi tanpa harmonisa yaitu sebesar 400,946 Watt. Dengan cara perhitungan yang sama, dapat dianalisis rugi-rugi daya untuk total transformator di Penyulang Menjangan dalam kondisi tanpa harmonisa yaitu sebesar 44708,180 Watt atau sama dengan 44,708 kW.

\section{F. Perhitungan Rugi-Rugi Penghantar Kondisi Dengan \\ Kandungan Harmonisa}

Untuk menghitung rugi-rugi daya saluran dengan kandungan harmonisa yang mengacu pada (5), dimana In yang dipakai adalah arus r.m.s (Irms) hasil eksekusi simulasi program ETAP. Sebagai contoh perhitungan rugi-rugi daya pada penghantar MVTIC 1 sebagai berikut.
Rugi - rugi daya tiga phasa pada saluran MVTIC 1 kondisi dengan kandungan harmonisa.

$\mathrm{I}_{\mathrm{rms}}$ (Arus harmonisa) $=89,39 \mathrm{~A}$.

$\mathrm{L}($ Panjang penghantar $)=6784 \mathrm{~m}=6,784 \mathrm{~km}$.

$\mathrm{R}$ (Tahanan) $\quad=0,265 \Omega / \mathrm{km} .6,784 \mathrm{~km}=1,79776 \Omega$

$$
\begin{aligned}
\Delta \mathrm{P} & =3 \times\left(\sum_{n=1}^{2} \mathrm{I}_{\mathrm{n}}^{2} \cdot \mathbb{R}_{\mathrm{n}}\right) \\
& =3 \times\left(\mathrm{I}_{\mathrm{rms}}\right)^{2} \cdot \mathrm{R} \\
& =3 \times(89,39)^{2} \times 1,79776 \\
& =43095,393 \mathrm{Watt} \\
& =43,0954 \mathrm{~kW}
\end{aligned}
$$

Rugi-rugi daya saluran line/cable MVTIC 1 sebesar 43,0954 kW. Dengan cara perhitungan yang sama seperti di atas, dapat dianalisis rugi-rugi total saluran pada Penyulang Menjangan kondisi dengan kandungan harmonisa adalah sebesar 200,7624 kW.

\section{G. Perhitungan Rugi-Rugi Transformator Kondisi Dengan Kandungan Harmonisa}

Perhitungan pengaruh harmonisa mengacu pada standar internasional (IEEE Std C57.110 ${ }^{\mathrm{TM}}$-2008). Untuk harmonisa kelipatan 3 seperti 3,6,9,12,15 dan seterusnya tidak

\begin{tabular}{|c|c|c|c|c|c|c|}
\hline $\begin{array}{c}\text { Orde } \\
\text { (n) }\end{array}$ & $\begin{array}{c}\left(\mathbf{I n} / \mathbf{I}_{1}\right. \\
)\end{array}$ & $\left(\operatorname{In} / \mathbf{I}_{1}\right)^{2}$ & $\left(n^{2}\right)$ & $\begin{array}{c}\left(\mathrm{In} / \mathbf{I}_{1}\right)^{2} * \\
\mathbf{n}^{2}\end{array}$ & $\left(\mathrm{n}^{0.8}\right)$ & $\left(\mathbf{I n} / \mathbf{I}_{1}\right)^{2} * n^{0}$ \\
\hline 1 & 1,000 & 1,000000 & 1 & 1,000000 & 1,0000 & 1,000000 \\
\hline 5 & 0,126 & 0,015876 & 25 & 0,396900 & 3,6239 & 0,057533 \\
\hline 7 & 0,078 & 0,006084 & 49 & 0,298116 & 4,74328 & 0,028858 \\
\hline 11 & 0,006 & 0,000036 & 121 & 0,004356 & 6,80948 & 0,000245 \\
\hline 13 & 0,012 & 0,000144 & 169 & 0,024336 & 7,78314 & 0,001121 \\
\hline 17 & 0,005 & 0,000025 & 289 & 0,007225 & 9,64626 & 0,000241 \\
\hline 19 & 0,006 & 0,000036 & 361 & 0,012996 & 10,5439 & 0,000380 \\
\hline Total & & 1,022201 & & 1,743929 & & 1,088378 \\
\hline
\end{tabular}
dimasukkan dalam perhitungan, karena hanya berpengaruh pada besarnya ukuran luas penampang konduktor pada titik netral. Sebagai contoh perhitungan rugi-rugi daya pada Trafo GR088 dengan kapasitas trafo adalah 100 kVA sebagai berikut.

TABEL V

PERHITUNGAN FAKTOR RUGI HARMONISA TRASFORMATOR GR088 PENYULANG MENJANGAN DALAM $(p u)$ KONDISI DENGAN KANDUNGAN HARMONISA

Dari table V didapatkan :

$$
\begin{aligned}
F_{\mathrm{HL}} & =\left(\sum_{\mathrm{n}=1}^{\mathrm{mak}}\left(\frac{\mathrm{I}_{\mathrm{n}}}{\mathrm{I}}\right)^{2} \mathrm{n}^{2}\right) /\left(\sum_{\mathrm{n}=1}^{\text {mak }}\left(\frac{\mathrm{I}_{\mathrm{n}}}{\mathrm{I}}\right)^{2}\right) \\
= & 1,743929 / 1,022201=1,706053 \mathrm{pu} \\
F_{\mathrm{HL}-\mathrm{STR}} & =\left(\sum_{\mathrm{n}=1}^{\text {mak }}\left(\frac{\mathrm{l}_{\mathrm{n}}}{\mathrm{I}_{\mathrm{L}}}\right)^{2} \cdot \mathrm{h}^{0.8}\right) /\left(\sum_{\mathrm{n}=1}^{\text {mak }}\left(\frac{\mathrm{L}_{\mathrm{n}}}{\mathrm{I}_{\mathrm{H}}}\right)^{2}\right) \\
& =1,088378 / 1,022201=1,06474 \mathrm{pu}
\end{aligned}
$$

Beban transformator GR88 tercatat 36,67 \% dari kapasitasnya sehingga :

$$
\begin{aligned}
& l_{\max }(p u)=\sqrt{\frac{P_{L L-R}(p u)}{1+\left[F_{H L} x P_{E C-R}(p u)\right]+\left[F_{H L-S T R} x P_{\text {OSL } \mathrm{R}}(p u)\right]}} \\
& 0,3667=\sqrt{P_{2 L}} / \sqrt{1,022201}
\end{aligned}
$$


$P_{L L}=0,137454(\mathrm{prl})$

TABEL VI

HASIL PERHITUNGAN RUGI-RUGI DAYA TRANSFORMATOR GR088 PENYULANG MENJANGAN DALAM KONDISI TANPA KANDUNGAN HARMONISA

\begin{tabular}{|c|c|c|c|c|}
\hline $\begin{array}{c}\text { Type Rugi- } \\
\text { Rgi }\end{array}$ & $\begin{array}{c}\text { Rugi } \\
\text { sesuai } \\
\text { Rating } \\
\text { (Watt) }\end{array}$ & $\begin{array}{c}\text { Rugi sesuai } \\
\text { Beban } \\
\text { Trafo } \\
\text { (Watt) }\end{array}$ & $\begin{array}{c}\text { Faktor } \\
\text { Harmonisa } \\
\text { (Watt) }\end{array}$ & $\begin{array}{c}\text { Koreksi } \\
\text { Rugi-Rugi } \\
\text { (Watt) }\end{array}$ \\
\hline $\begin{array}{c}\text { Tidak } \\
\text { berbeban }\end{array}$ & 210 & 210 & & 210 \\
\hline $\begin{array}{c}\text { Rugi Ohmik } \\
\text { (I'R) }\end{array}$ & 95,777 & 13,165 & & 13,165 \\
\hline $\begin{array}{c}\text { Rugi arus } \\
\text { eddy }\end{array}$ & 436,993436 & 60,067 & 1,706053 & 102,4768 \\
\hline $\begin{array}{c}\text { Rugi Sasar } \\
\text { Lain }\end{array}$ & 887,2291 & 121,953 & 1,06474 & 129,849 \\
\hline Rugi Total & & & & $\mathbf{4 5 5 , 4 9 0}$ \\
\hline
\end{tabular}

\section{H. Perbandingan Hasil Perhitungan Rugi-Rugi Daya Total}

Total beban sesuai data hasil pengukuran beban transformator Penyulang Menjangan oleh PT. PLN (Persero) Rayon Gilimanuk sebesar 3665,91 kVA dengan cos phi sebesar 0,946 sehingga total beban adalah 3493,608 kW. Besarnya rugi - rugi daya pada jaringan distribusi Penyulang Menjangan jika dinyatakan dalam prosentase adalah sebagai berikut.

\% Rugi days $=\frac{\text { Total rugi daya pd faringan distribusi }}{\text { Total Beban Ronsumen Distribusi }} \times 100 \%$

Perbandingan hasil perhitungan rugi - rugi daya di Penyulang Menjangan terlihat pada table VII.

TABEL VII

PERBANDINGAN RUGI - RUGI DAYA DI PENYULANG MENJANGAN

\begin{tabular}{|c|c|c|c|c|c|}
\hline $\begin{array}{c}\text { Nama } \\
\text { Penyulang }\end{array}$ & Kondisi & $\begin{array}{c}\text { Rugi } \\
\text { Saluran } \\
(\mathbf{k W})\end{array}$ & $\begin{array}{c}\text { Rugi } \\
\text { Trafo } \\
(\mathbf{k W})\end{array}$ & $\begin{array}{c}\text { Rugi Daya } \\
\text { Total } \\
(\mathbf{k W})\end{array}$ & $\begin{array}{c}\text { Rugi Daya } \\
\text { Total } \\
(\%)\end{array}$ \\
\hline Menjangan & $\begin{array}{c}\text { Tanpa } \\
\text { Harmonisa }\end{array}$ & 199,6573 & 44,708 & 244,3653 & 6,995 \\
\hline Menjangan & Harmonisa & 200,7624 & 45,402 & 246,1644 & 7,046 \\
\hline Selisih & & & & 1,7991 & \\
\hline
\end{tabular}

I. Analisis Sumber Harmonisa Pada Penyulang Menjangan

Dari data hasil pengukuran THDarus (THDi) Penyulang Menjangan dapat diketahui bahwa Gardu Distribusi yang terletak di pangkal yaitu GR088 dan GR079 memiliki kandungan haromisa yang tertinggi.

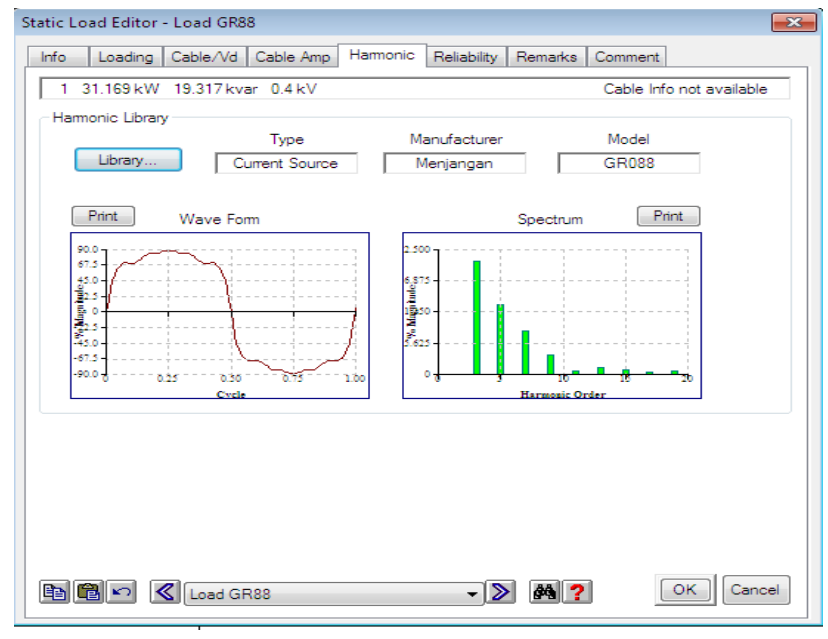

Gambar 1: Tampilan kurva gelombang dan spectrum harmonisa pada transformator GR088 Penyulang Menjangan

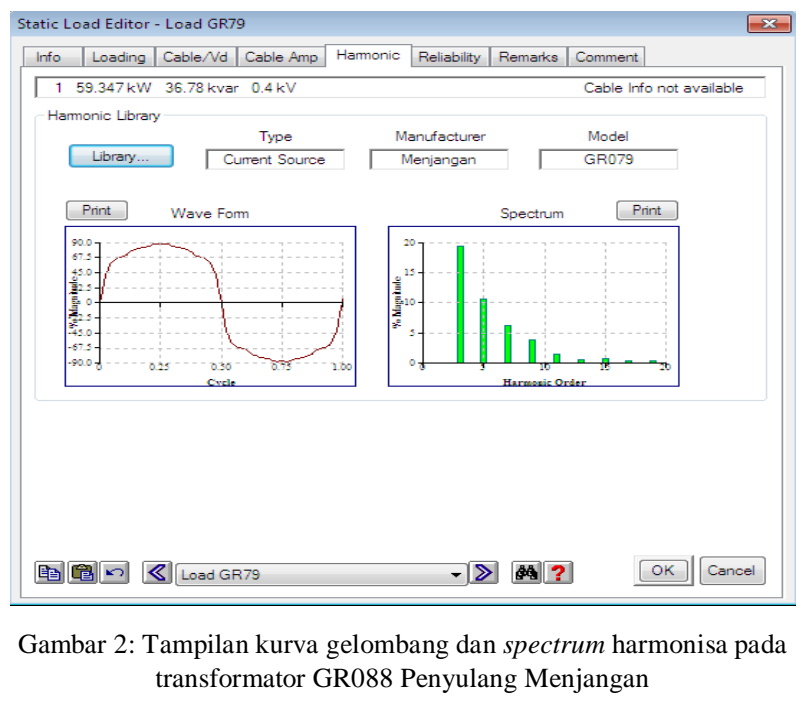

Dari gambar 1 dan 2 terlihat pola kurva gelombang dan spectrum pada GR088 dan GR079 identik dengan sumber harmonik dari Beban Komersial dan Fasilitas komersial seperti beban rumah tangga, kantor yang kompleks, pusat perbelanjaan, rumah sakit, dan akses data intern didominasi oleh lampu flourecent dengan ballast elektronik, Pengatur kecepatan (adjustable-speed driver) digunakan pada pemanasan (heating), Ventilasi (Ventilation), dan pendingin ruangan (AC) dan peralatan elektronik sensitive lainnya pada umumnya disuplai dari single-phase switchmode power supplies. Namun selain dari beban sumber penyebab timbulnya harmonisa, perlu dipertimbangkan juga aspek polusi yang dapat menimbulkan partial discharge pada isolator, sehingga berpengaruh terhadap besarnya harmonisa. 


\section{KESIMPULAN}

Berdasarkan pembahasan yang telah dilakukan terebut, dapat diambil beberapa kesimpulan sebagai berikut :

1. Dari hasil pengukuran kandungan harmonisa arus pada Penyulang Menjangan diketahui transformator distribusi pada pangkal penyulang yaitu GR088 dan GR079, memiliki kandungan harmonisa arus yang tertinggi.

2. Rugi-rugi daya pada Penyulang Menjangan dipengaruhi oleh kandungan harmonisa arus dengan selisih antara rugi-rugi daya pada kondisi tanpa kandungan harmonisa dan rugi-rugi daya pada kondisi dengan kandungan hamonisa adalah 1,7991 kW. Selisih rugi-rugi daya tersebut disebabkan oleh perbedaan arus fundamental dan arus harmonisa yang mengalir pada jaringan sistem distribusi $20 \mathrm{kV}$ Penyulang Menjangan akibat adanya kandungan harmonisa arus.

3. Berdasarkan pola kurva gelombang dan spectrum kandungan harmonisa pada transformator GR088 dan GR079 di Penyulang Menjangan, sumber harmonisa identik dengan pola kurva gelombang dan spectrum yang dihasilkan dari Beban Komersial dan Fasilitas komersial seperti beban rumah tangga serta peralatan elektronik sensitive yang pada umumnya disuplai dari single-phase switchmode power supplies (SMPS).

\section{UCAPAN TERIMAKASIH}

Pertama-tama perkenankanlah penulis memanjatkan puji syukur ke hadapan Ida Sang Hyang Widhi Wasa/ Tuhan Yang Maha Esa, karena hanya atas asung wara nugraha-Nya/kurniaNya, skripsi ini dapat diselesaikan. Penulis mengucapkan terima kasih yang sebesar-besarnya kepada Dekan Fakultas Teknik Universitas Udayana yang dijabat oleh Bapak Prof. Ir. Ngakan Putu Gede Suardana, MT., Ph.D., atas kesempatan yang diberikan kepada penulis untuk menjadi mahasiswa pada Fakultas Teknik Universitas Udayana. Ucapan terima kasih ini ditujukan kepada Bapak Ir. I Wayan Sukerayasa, MT., pembimbing I dan Bapak Wayan Gede Ariastina, ST., MengSc., Ph.D., Pembimbing II yang dengan penuh perhatian telah memberikan dorongan, semangat, bimbingan, dan saran selama penulis mengikuti program sarjana. Terima kasih sebesar-besarnya pula penulis sampaikan kepada orang tua, adik, pacar, dan teman-teman yang dengan penuh pengorbanan telah memberikan kepada penulis kesempatan untuk lebih berkonsentrasi menyelesaikan tugas akhir ini.

\section{REFERENSI}

[1] PT. PLN(Persero). "Susut Distribusi Bali tahun 2015". Bali. 2015

[2] Sumaryadi, "Management Asset, Upaya Mempertahankan Unjuk Kerja Transformator Terhadap Pengaruh Harmonisa Pada Sistem Tenaga Listrik”. Bandung : Program Studi Magister Teknologi dan Bisnis Kelistrikan Institut Teknologi Bandung. 2009.

[3] International Electrotechnical Commision (IEC) 6100-2-11990, "Electromagnetic Compatibility", 1990.

[4] IEEE 1159-1995 standard", IEEE Recommended Practices for Monitoring Electric Power Quality,"1995.

[5] Rinas. I. W. "Penggunaan Metode Urutan (Sequence Method) Pada Analisis Harmonisa Untuk Sistem Kelistrikan Tak-Seimbang". Staf Pengajar Teknik Elektro Fak. Teknik Universitas Udayana, Jimbaran Bali.2007

I D. G. Wisnu Agung Bayuna: Studi Analisis Pengaruh Harmonisa
[6] A.I. Weking, I W. Rinas, A. K. Suwardana, "Simulasi Penentuan Penempatan Filter Aktif Shunt Untuk Mendapatkan Distorsi Daya Yang Terkecil Di Blue Point Bay Villa \& Spa". 2013

[7] Dugan, Rizy, "Harmonic Considerations for Electrical Distribution Feeders", National Technical Information Service, Report No. ORNL/Sub/81-95011/4 (Cooper Power Systems as Bulletin 87011, "Electrical Power System Harmonics, Design Guide"). 2001.

[8] Syahwil M, dkk. "Studi Dampak Harmonisa Terhadap Susut Teknis Pada Industri Semen (Kasus Industri Semen Tonasa)”. Makassar : Magister Student of Hasanuddin University. 2010.

[9] Arrillaga, J. and Watson, N. R, "Power System Harmonic Analysis. New Zealand". University of Canterbury. 2000.

[10] IEEE Std C57.91-1993, "Standard Test Code for Liquid-Immersed Distribution, Power, and Regulating Transformers and Guide for Short-Circuit Testing", 1993

[11] IEEE Std C57.91-1995,"Loading Guide for Mineral Oil Immersed", 1995

[12] IEEE Std C57.110 ${ }^{\mathrm{TM}}-1998$, , Recommended Practice for Establishing Liquid-Filled and Dry-Type Power and Distribution Transformer Capability When Supplying Nonsinusoidal Load Current”, 2008. 
\{ halaman ini sengaja dikosongkan \} 